\title{
Fruit and vegetable intakes in a sample of pre-school children participating in the 'Five for All' project in Bradford
}

\author{
JE Cockroft ${ }^{1, *}$, M Durkin $^{2}, \mathrm{C} \mathrm{Masding}^{3}$ and JE Cade ${ }^{1}$ \\ ${ }^{1}$ Nutritional Epidemiology Group, Centre for Epidemiology and Biostatistics, The University of Leeds, 30/32 Hyde \\ Terrace, Leeds LS2 9LN, UK: ${ }^{2}$ Airedale Primary Care Trust, Community Health Team, Millennium Park, Station Road, \\ Steeton, Keighley, BD20 6RB, UK: ${ }^{3}$ Bradford South \& West Primary Care Trust, 10/1 1 Neville House, Neville Road, \\ Bradford BD4 8TU, UK
}

Submitted 1 November 2004: Accepted 15 March 2005

\begin{abstract}
Background: Longitudinal research has shown that eating fruit and vegetables during childhood has a positive impact on long-term health outcome from heart disease and asthma. However, recommendations for fruit and vegetable intakes in pre-school children are not as explicit as those for adults and few data exist on actual intakes of fruit and vegetables in this particular age group.

Aims: To describe fruit and vegetable intakes in the daily diets of a sample of pre-school children in Bradford, West Yorkshire, and to compare the findings with existing national UK data.

Subjects: Pre-school children aged 3 and 4 years $(n=207)$. All subjects attended nurseries in the Airedale and Bradford South and West regions at the time of the study. Design: Dietary data were collected using the pre-validated CADET (Child and Diet Evaluation Tool) diary. All children were also seen individually in order to assess their awareness and preference for a range of fruit and vegetables.

Results: Intakes of fruit and vegetables in this sample of pre-school children were below recommended levels. Only 16\% of children in this sample were successfully eating fruit and vegetables on five occasions a day and conversely $14 \%$ ate no fruit and vegetables at all. Vegetable intakes were far lower than fruit intakes with $39 \%$ of the sample consuming no vegetables. There were statistically significant differences in median fruit and vegetable intakes between children with different demographic and lifestyle variables, such as which nursery they attended and what the highest educational qualification in the household was. Children's awareness of and preferences for different fruit and vegetables significantly affected their median intakes of fruit and vegetables.

Conclusion: Fruit and vegetable intakes in this sample of pre-school children were far lower than the recommended levels of 5 portions a day. A greater diversity of intakes should be encouraged and these data suggest that this may be attained by increasing children's awareness by exposing them to a wider range of fruit and vegetables.
\end{abstract}

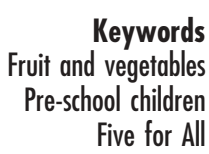

Five for All
Non-communicable diseases including cardiovascular disease, type II diabetes, cancer and obesity account for some $60 \%$ of global deaths and almost half (47\%) of the global burden of disease ${ }^{1}$. Decreasing the prevalence of these diseases is therefore an important public health goal, and this is embodied in current policies such as the World Health Organization's (WHO) Global Strategy on Diet, Physical Activity and Health ${ }^{2}$. A high consumption of fruit and vegetables is considered to be beneficial to health and there is now a comprehensive body of evidence recognising the protective effects of high fruit and vegetable consumption on cardiovascular diseases and certain types of cancer ${ }^{3-5}$. Low fruit and vegetable intake is among the top 10 selected risk factors for global mortality and it is estimated that up to 2.7 million lives world-wide could potentially be saved each year if fruit and vegetable consumption were sufficiently increased ${ }^{6}$.

With the increasing recognition that fruit and vegetables are beneficial to health, official recommendations have been made as to the desirable quantities of fruit and vegetables that people should consume. In 1990 the WHO recommended that a total intake of $400 \mathrm{~g}$ per person per day should be included in the diet to provide protection against chronic diseases ${ }^{7}$. However, there were no UK national goals for fruit and vegetable consumption until publication of the report on the nutritional aspects of cardiovascular disease by the Committee on Medical Aspects of Food and Nutrition Policy (COMA) in 1994. 
This report advised a 50\% increase in the mean population intake of fruit and vegetables in the $\mathrm{UK}^{8}$. This was backed up by a further COMA report in 1998, focusing on the nutritional aspects of cancer, which recommended a $50 \%$ increase in fruit and vegetable consumption, to at least 5 portions per person per day 9 . This advice is in line with the WHO recommendation of $400 \mathrm{~g}$, if we assume an average portion size of $80 \mathrm{~g}$. The advice is based on the fact that this is a potentially achievable goal and will be conducive to better general health, in the absence of sufficient evidence to quantify the optimal level of intake to reduce disease risk $^{9,10}$.

There is some evidence to suggest that dietary habits learnt in infancy can influence preferences and practices in later life, and further evidence suggests fair to moderate tracking of food habits from childhood to adolescence $^{11-13}$. Data on tracking of nutrient intakes are variable; however, this could be partly due to the problematic issue of dietary assessment methodologies ${ }^{14,15}$. One study investigating the tracking of food intake patterns, including fruit and vegetable consumption, over a 6-year period from childhood to adolescence reported maintenance of dietary patterns into adolescence and concluded that efforts to promote a healthy diet should start in childhood $^{11}$. Furthermore, longitudinal research has shown that eating fruit and vegetables during childhood has a positive impact on long-term health outcome from heart disease ${ }^{16}$ and asthma ${ }^{17}$. However, recommendations for fruit and vegetable intakes in preschool children are not as explicit as those made for adults. Recommendations in COMA's 1994 report on the nutritional aspects of cardiovascular disease only suggest that children should begin to eat more fruit and vegetables from the age of 2 years, so that by the time they are 5 years old they should fully meet the target of 'at least five a day' But no guidelines are given as to how big or small a child's portion should be in comparison to the $80 \mathrm{~g}$ portion used in the adult recommendations.

Limited data currently exist on actual intakes of fruit and vegetables in this age group, or how intake might vary between certain subgroups of the population. This makes it difficult to target health promotion strategies effectively. The data presented here aim to describe fruit and vegetable intakes in the daily diets of a sample of pre-school children in Bradford, West Yorkshire.

\section{Subjects and methods}

\section{Study population}

The data for this study were obtained from the baseline results of the 'Five for All' project. This project was initiated to develop and evaluate a novel intervention designed to promote fruit and vegetable consumption in pre-school children, aged 3-5 years. Nurseries were recruited via attendance at a monthly meeting of local nursery staff where the research team gave a brief presentation of the study. This was an easy way to access a large number of local nurseries and is therefore based on a convenience sample. Interested nurseries were asked to complete an expression of interest form, or to call the research team for further information. Eight nurseries from the Airedale and Bradford South and West regions were recruited to the 'Five for All' project. The research team visited all nurseries to give a brief presentation and a question and answer session for all nursery staff.

Once nurseries had been recruited eligible parents were contacted. Eligible parents were those with children aged 3 and 4 years attending nursery. Parents were contacted via an introductory letter and a parent's information leaflet. If parents were happy for their child to take part in the study, they were asked to sign a consent form and send it back to the nursery. Across the eight participating nurseries, 254 parents consented to their children taking part in the 'Five for All' study.

\section{Data collection}

Ethical committee approval was obtained for the study from the Local Research Ethics Committee in both Airedale and Bradford South and West. Dietary data were collected using the CADET (Child and Diet Evaluation Tool) diary, previously known as the PEARS (Pupil Eating Assessment Research in Schools) tool. This diary has been prevalidated for use with this age group ${ }^{18}$. CADET is a validated tool that measures changes in total daily consumption of fruit and vegetables and overall diet amongst children aged 3-7 years. The diary is designed to prospectively record what children eat and drink at different meal events over a $24 \mathrm{~h}$ period by means of ticks which are placed next to all food and drink consumed at meal and snack times. Adults (research staff and parents) complete CADET on behalf of the children. Baseline data collection took place between March and May 2004. The research team visited each nursery and completed a CADET diary on behalf of each individual child whilst the child was at nursery. As each child left nursery the CADET diaries were given to the child's parent(s) in order for them to complete the rest of the day's food consumed at home, as well as a retrospective account of breakfast for that morning. The CADET diaries also included a number of additional questions about the child's diet and further questions about the make-up of each child's household. Parents were asked to return the CADET diaries back to the nursery the following day.

All children were also seen individually by a member of the research team to assess their awareness and preference for a range of fruit and vegetables. Children were asked to come and play a food game at which time they were shown seven different fruits and vegetables (apple, banana, strawberry, pear, broccoli, carrot and cauliflower). Each child was first asked if they could name the fruit or vegetable, and secondly if they liked to eat that particular fruit or vegetable. From this information fruit 
and vegetable awareness and preference scores for each child were generated. This was done simply by scoring a 1 for a correct response and a 0 for an incorrect or 'don't know' response for the identification score, and by scoring a 1 for a 'yes' response and a 0 for a 'no' response for the preference score. With seven fruits and vegetables being assessed, scores could thus range from 0 to 7 for combined fruit and vegetable scores. Higher ranging scores would represent greater liking of fruit and vegetables or a greater knowledge of fruit and vegetable names.

\section{Statistical methods and design}

CADET diaries were analysed for both types and amounts of fruits (including fruit juice) and vegetables (excluding potatoes and including beans and pulses). The CADET diary does not ask participants to record actual portion sizes for foods on the tick list, instead portion sizes are applied to the foods during analysis. The portion size data have been derived from the results of a large national survey of children's diets ${ }^{19}$ and were provided by Dr Adamson from Newcastle University and Dr Wreiden from Dundee University, who worked on projects for the Food Standards Agency which sought to develop children's portion sizes. Fruit and vegetable intakes were recorded as both a simple eating frequency count (the number of times a fruit or vegetable was eaten) and also as an amount in grams. However, as the target is for all children to be eating 5 portions a day, the data of interest are the eating frequency counts as opposed to the total amounts in grams. Indeed the totals are only included for comparison purposes.

Initial analyses were carried out using the Statistical Package for the Social Sciences version 10.0 (SPSS Inc., Chicago, IL, USA, 1998). For the purpose of analysis, median intakes of fruit and vegetables were examined due to the skewed nature of the data. Median intakes of fruit and vegetables were compared with socio-economic, demographic and lifestyle variables, including fruit and vegetable awareness and preference scores, using the Kruskal-Wallis or Mann-Whitney test as appropriate.

\section{Results}

Out of 280 eligible pre-school children attending participating nurseries, 254 (91\%) positive consents were received from parents. From these 254 we received 209 (82\%) completed CADET diaries. Subsequently two subjects, considered to be extreme outliers due to unreliable data, were excluded from the analysis. The dataset for analysis therefore contained 207 subjects.

The sample characteristics are shown in Table 1 . There are relatively even numbers of males (49\%) and females (51\%). The South Asian population is under-represented in this sample, making up around $10 \%$ of the total. In this study sample over a quarter of all households had no formal qualifications (27.5\%) and a quarter of all
Table 1 Sample characteristics

\begin{tabular}{|c|c|c|c|c|c|c|}
\hline & \multicolumn{2}{|c|}{$\begin{array}{c}\text { Boys } \\
(n=101)\end{array}$} & \multicolumn{2}{|c|}{$\begin{array}{c}\text { Girls } \\
(n=106)\end{array}$} & \multicolumn{2}{|c|}{$\begin{array}{c}\text { All } \\
(n=207)\end{array}$} \\
\hline & $n$ & $\%$ & $n$ & $\%$ & $n$ & $\%$ \\
\hline \multicolumn{7}{|l|}{ Nursery ID } \\
\hline 1 & 25 & 24.8 & 27 & 25.5 & 52 & 25.1 \\
\hline 2 & 4 & 4.0 & 8 & 7.5 & 12 & 5.8 \\
\hline 3 & 9 & 8.9 & 6 & 5.7 & 15 & 7.2 \\
\hline 4 & 21 & 20.8 & 23 & 21.7 & 44 & 21.3 \\
\hline 5 & 4 & 4.0 & 4 & 3.8 & 8 & 3.9 \\
\hline 6 & 4 & 4.0 & 3 & 2.8 & 7 & 3.4 \\
\hline 7 & 21 & 20.8 & 23 & 21.7 & 44 & 21.3 \\
\hline 8 & 13 & 12.9 & 12 & 11.3 & 25 & 12.1 \\
\hline \multicolumn{7}{|l|}{ Age of child } \\
\hline 3 years & 47 & 46.5 & 68 & 64.2 & 115 & 55.6 \\
\hline 4 years & 54 & 53.5 & 38 & 35.8 & 92 & 44.4 \\
\hline \multicolumn{7}{|l|}{ Ethnicity } \\
\hline White UK & 80 & 89.9 & 89 & 86.4 & 169 & 88.0 \\
\hline White European & 1 & 1.1 & 1 & 1.0 & 2 & 1.0 \\
\hline White other & 0 & 0.0 & 1 & 1.0 & 1 & 0.5 \\
\hline Black Caribbean & 0 & 0.0 & 1 & 1.0 & 1 & 0.5 \\
\hline Indian & 1 & 1.1 & 0 & 0.0 & 1 & 0.5 \\
\hline Pakistani & 7 & 7.9 & 11 & 10.7 & 18 & 9.4 \\
\hline \multicolumn{7}{|c|}{$\begin{array}{l}\text { Does anyone living in the child's household have a degree level of } \\
\text { education or above? }\end{array}$} \\
\hline No & 25 & 24.8 & 32 & 30.2 & 57 & 27.5 \\
\hline O-level/GCSE & 26 & 25.7 & 21 & 19.8 & 47 & 22.7 \\
\hline $\begin{array}{l}\text { National vocational } \\
\text { qualifications }\end{array}$ & 26 & 25.7 & 29 & 27.4 & 55 & 26.6 \\
\hline A-level & 12 & 11.9 & 14 & 13.2 & 26 & 12.6 \\
\hline Degree & 12 & 11.9 & 10 & 9.4 & 22 & 10.6 \\
\hline \multicolumn{7}{|c|}{ Does anyone living in the child's household have a paid job? } \\
\hline Yes & 68 & 77.3 & 73 & 73.7 & 141 & 75.4 \\
\hline No & 20 & 22.7 & 26 & 26.3 & 46 & 24.6 \\
\hline \multicolumn{7}{|c|}{ Number of adults (over $18 \mathrm{~s}$ ) living in the child's household } \\
\hline 1 & 12 & 13.8 & 19 & 19.2 & 31 & 16.7 \\
\hline 2 & 69 & 79.3 & 68 & 68.7 & 137 & 73.7 \\
\hline $3+$ & 6 & 6.9 & 12 & 12.1 & 18 & 9.7 \\
\hline
\end{tabular}

households were without paid employment (24.6\%). Of these pre-school children, $16.7 \%$ lived in single-parent households.

Intakes of fruit and vegetables in this sample of preschool children were below recommended levels. The percentages of children achieving differing eating frequencies (from 0 occasions to $5+$ occasions) of fruit and vegetables are shown in Table 2 . Only $20 \%$ of children in this sample were successfully eating fruit and vegetables on five occasions a day and conversely $11 \%$ ate no fruit and vegetables at all on the day the diaries were recorded. It can also be seen from Table 2 that vegetable intakes were far lower than fruit intakes, with $38.6 \%$ of the sample consuming no vegetables at all on the recording day.

Table 3 shows median intakes of fruit and vegetables according to various demographic and lifestyle variables. There were inadequate numbers of children within each ethnic group to be able to obtain precise estimates of the median. However, there were statistically significant differences in fruit and vegetables intakes between children in different nurseries, with median intakes ranging from $90 \mathrm{~g} \mathrm{day}^{-1}$ in one nursery up to $270 \mathrm{~g} \mathrm{day}^{-1}$ in another $(P<0.01)$. The only other statistically 
Table 2 Percentage of children achieving differing daily eating frequencies of fruit and vegetables

\begin{tabular}{|c|c|c|c|c|c|c|c|c|c|}
\hline \multirow[b]{2}{*}{ Eating frequency } & \multicolumn{3}{|c|}{$\begin{array}{l}\text { Fruit (including one portion } \\
\text { of fruit juice) }\end{array}$} & \multicolumn{3}{|c|}{ Vegetables (excluding potatoes) } & \multicolumn{3}{|c|}{ Fruit and vegetables } \\
\hline & $n$ & $\%$ & Cumulative \% & $n$ & $\%$ & Cumulative \% & $n$ & $\%$ & Cumulative \% \\
\hline 0 & 40 & 19.3 & 19.3 & 80 & 38.6 & 38.6 & 22 & 10.6 & 10.6 \\
\hline 1 & 62 & 30.0 & 49.3 & 60 & 29.0 & 67.6 & 41 & 19.8 & 30.4 \\
\hline 2 & 45 & 21.7 & 71.0 & 45 & 21.7 & 89.4 & 29 & 14.0 & 44.4 \\
\hline 3 & 32 & 15.5 & 86.5 & 13 & 6.3 & 95.7 & 35 & 16.9 & 61.4 \\
\hline 4 & 17 & 8.2 & 94.7 & 5 & 2.4 & 98.1 & 39 & 18.8 & 80.2 \\
\hline $5+$ & 11 & 5.3 & 100.0 & 4 & 1.9 & 100.0 & 41 & 19.9 & 100.0 \\
\hline
\end{tabular}

significant variable was the highest education level in the child's household. Children from households with qualifications of A-level or above consumed significantly more fruit and vegetables than did children from households with a lower educational attainment $(P<0.01)$.

Figure 1 shows the percentage of the sample consuming each type of fruit as recorded in the CADET diary. This shows that bananas and apples were the most commonly eaten fruits among this particular age group and that fruit juice was a significant contributor to fruit intake within this age range. In Fig. 2 it can be seen that peas, sweet corn and carrots were the most popular vegetables excluding potatoes.

Figure 3 shows the percentage of the sample able to recognise each of the fruits and vegetables shown to them, coupled with the data on preferences for these same foods. This shows that although $97 \%$ of the sample was able to name the apple and the banana, only $45 \%$ could name the broccoli and just $21 \%$ correctly named the cauliflower. This figure also shows that if children were able to name the fruit or vegetable correctly then they were also more likely to state a liking for that fruit or vegetable. So fruits and vegetables that were less well

Table 3 Median daily amount of fruit and vegetables consumed according to various demographic and lifestyle factors

\begin{tabular}{|c|c|c|c|c|c|c|c|c|c|c|c|c|}
\hline & \multicolumn{4}{|c|}{ Fruit intake (g) } & \multicolumn{4}{|c|}{ Vegetable intake (g) } & \multicolumn{4}{|c|}{ Fruit and vegetable intake (g) } \\
\hline & Median & $95 \% \mathrm{Cl}$ & IQR & $P$-value & Median & $95 \% \mathrm{Cl}$ & IQR & $P$-value & Median & $95 \% \mathrm{Cl}$ & IQR & $P$-value \\
\hline \multicolumn{13}{|l|}{ Sex of child } \\
\hline Male & 118 & $80-154$ & $0-208$ & \multirow[t]{2}{*}{0.79} & 33 & $27-51$ & $0-71$ & \multirow[t]{2}{*}{0.81} & 165 & $125-200$ & $76-269$ & \multirow[t]{2}{*}{0.77} \\
\hline Female & 125 & $77-138$ & $67-194$ & & 29 & $28-49$ & $0-65$ & & 159 & $134-196$ & $72-270$ & \\
\hline \multicolumn{13}{|l|}{ Age of child } \\
\hline 3 years & 111 & $77-134$ & $62-191$ & \multirow[t]{2}{*}{0.35} & 28 & $28-51$ & $0-74$ & \multirow[t]{2}{*}{0.68} & 163 & $119-194$ & $71-265$ & \multirow[t]{2}{*}{0.53} \\
\hline 4 years & 129 & $80-151$ & $68-220$ & & 32 & $28-40$ & $0-68$ & & 158 & $131-211$ & $81-278$ & \\
\hline \multicolumn{13}{|l|}{ Nursery ID } \\
\hline 1 & 112 & $72-142$ & $63-191$ & \multirow{8}{*}{$<0.01$} & 51 & $31-61$ & $24-75$ & \multirow[t]{8}{*}{$<0.01$} & 175 & $131-216$ & $76-261$ & \multirow{8}{*}{$<0.01$} \\
\hline 2 & 194 & $112-334$ & $115-324$ & & 17 & $0-52$ & $0-52$ & & 234 & $113-337$ & $116-332$ & \\
\hline 3 & 237 & $150-254$ & $147-254$ & & 33 & $29-81$ & $28-83$ & & 270 & $227-284$ & $225-286$ & \\
\hline 4 & 75 & $62-128$ & $0-181$ & & 0 & $0-28$ & $0-57$ & & 90 & $66-165$ & $27-218$ & \\
\hline 5 & 155 & $38-330$ & $77-295$ & & 11 & $0-72$ & $0-37$ & & 177 & $51-375$ & $78-295$ & \\
\hline 6 & 77 & $0-201$ & $0-183$ & & 101 & $18-156$ & $58-150$ & & 150 & $64-331$ & $77-310$ & \\
\hline 7 & 75 & $62-133$ & $61-182$ & & 28 & $6-49$ & $0-59$ & & 117 & $83-169$ & $71-221$ & \\
\hline 8 & 149 & $80-217$ & $79-248$ & & 54 & $28-79$ & $18-97$ & & 200 & $149-291$ & $112-306$ & \\
\hline \multicolumn{13}{|l|}{$\begin{array}{l}\text { Highest education level in } \\
\text { household }\end{array}$} \\
\hline No qualifications & 77 & $69-128$ & $0-190$ & \multirow{5}{*}{$<0.01$} & 5 & $0-28$ & $0-55$ & \multirow[t]{5}{*}{$<0.01$} & 111 & $71-164$ & $44-227$ & \multirow{5}{*}{$<0.01$} \\
\hline O-level/GCSE & 82 & $71-128$ & $61-153$ & & 28 & $0-50$ & $0-65$ & & 149 & $89-175$ & $71-222$ & \\
\hline $\begin{array}{l}\text { National vocational } \\
\text { qualifications }\end{array}$ & 125 & $76-172$ & $62-237$ & & 33 & $29-59$ & $23-79$ & & 174 & $128-228$ & $80-280$ & \\
\hline A-level & 175 & $127-250$ & $108-283$ & & 57 & $50-87$ & $31-91$ & & 281 & $162-336$ & $160-343$ & \\
\hline Degree & 163 & $109-223$ & $80-240$ & & 40 & $27-58$ & $24-60$ & & 204 & $143-272$ & $128-304$ & \\
\hline \multicolumn{13}{|l|}{$\begin{array}{l}\text { Employment status } \\
\text { of household }\end{array}$} \\
\hline No paid job in household & 77 & $71-130$ & $62-194$ & \multirow[t]{2}{*}{0.23} & 28 & $20-33$ & $0-58$ & \multirow[t]{2}{*}{0.14} & 138 & $94-170$ & $71-224$ & \multirow[t]{2}{*}{0.12} \\
\hline Paid job in household & 128 & $109-150$ & $64-205$ & & 36 & $28-53$ & $0-78$ & & 176 & $149-202$ & $83-271$ & \\
\hline \multicolumn{13}{|l|}{$\begin{array}{l}\text { Number of adults in } \\
\text { household }\end{array}$} \\
\hline 1 & 129 & $72-201$ & $71-221$ & \multirow[t]{3}{*}{0.74} & 28 & $27-50$ & $23-78$ & \multirow[t]{3}{*}{0.57} & 174 & $129-228$ & $99-270$ & \multirow[t]{3}{*}{0.76} \\
\hline 2 & 122 & $80-138$ & $62-205$ & & 33 & $29-54$ & $0-77$ & & 165 & $134-198$ & $76-274$ & \\
\hline $3+$ & 133 & $63-167$ & $62-172$ & & 28 & $0-57$ & $0-58$ & & 147 & $97-220$ & $89-224$ & \\
\hline
\end{tabular}

$\mathrm{CI}$ - confidence interval; IQR - interquartile range. 


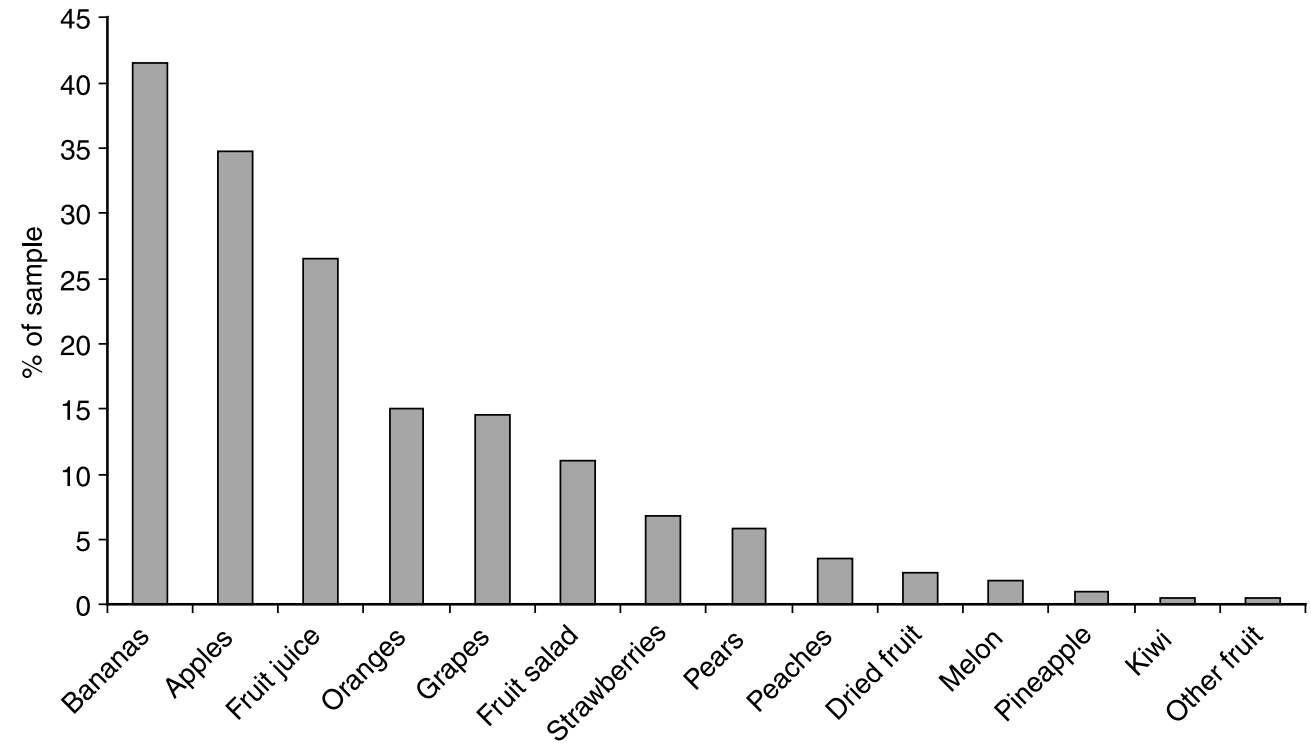

Fig. 1 Percentage of the sample consuming each type of fruit

known, such as pears and cauliflower, were also the fruits and vegetables that were less well liked. Table 4 also concerns the awareness and preference scores. It can be seen that as fruit awareness and preference scores increased so did median intakes of fruit $(P<0.01)$. This same pattern can be seen for vegetables $(P<0.01)$ (Table 5).

\section{Discussion}

It should be noted that the South Asian population of Bradford is under-represented in this sample. In Bradford South and West Primary Care Trust (PCT) 13\% of 0-4-yearolds are South Asian and in Airedale PCT this figure rises to $22 \%$. In the population under study only $9 \%$ reported their child's ethnicity as South Asian. A further limiting factor is the timing of this study. The recording days all took place between March and May 2004 and therefore seasonal variation in fruit and vegetable intake cannot be allowed for. However, taking these limitations into account, this paper describes the fruit and vegetable intake in the daily diets of a sample of pre-school children in Bradford, West Yorkshire.

As previously reported, recommendations for fruit and vegetable intakes in pre-school children are not as explicit as those that exist for adults ${ }^{7}$. Recommendations in COMA's 1994 report on the nutritional aspects of cardiovascular disease only suggest that children should

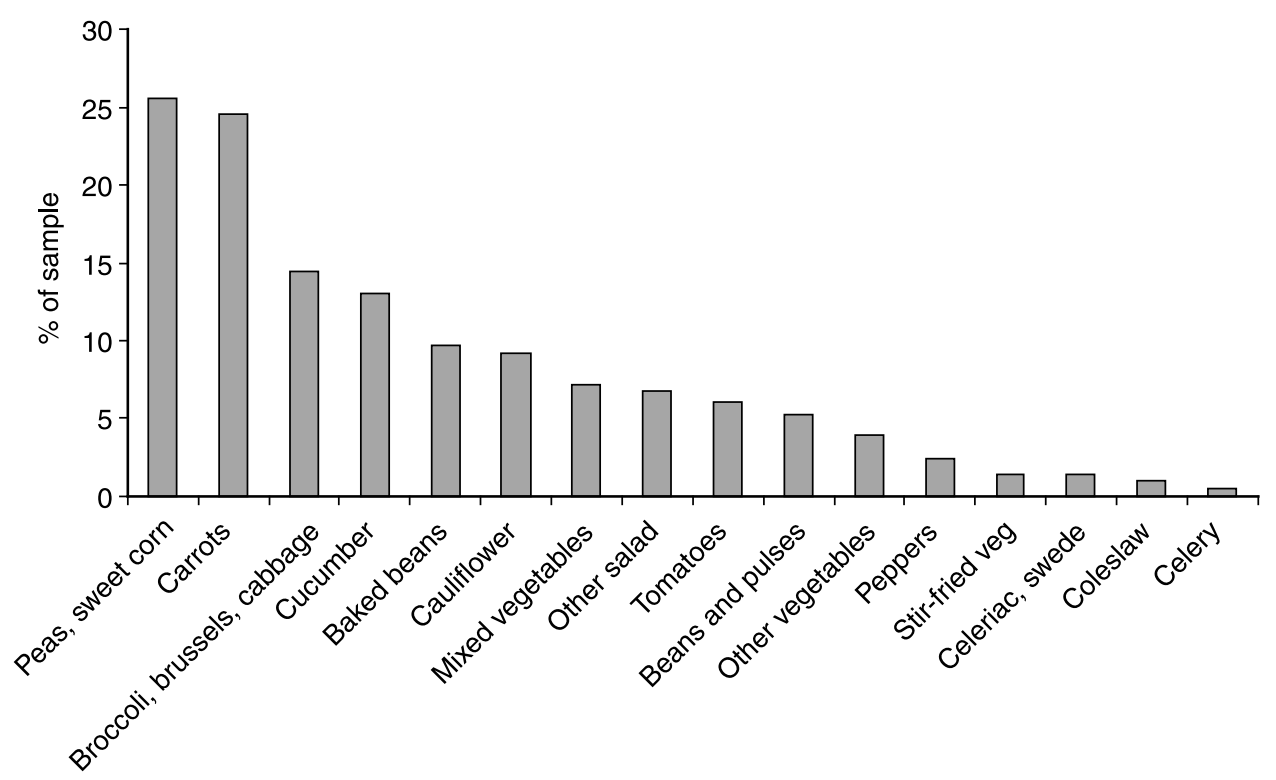

Fig. 2 Percentage of the sample consuming each type of vegetable 


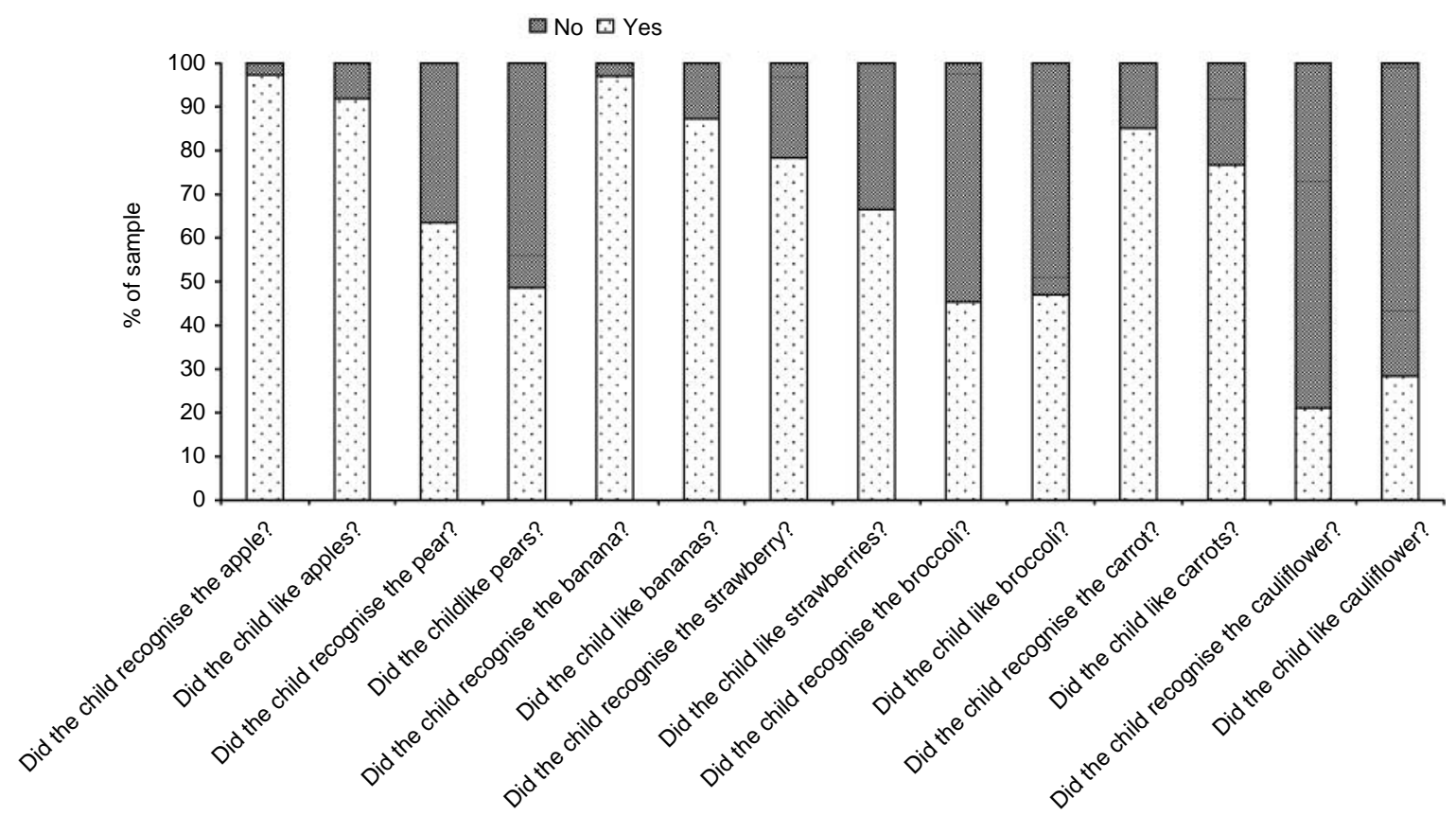

Fig. 3 Comparison of percentages of the sample able to recognise different fruits and vegetables and those liking or disliking the same fruits and vegetables

begin to eat more fruit and vegetables from the age of 2 years, so that by the time they are 5 years old they should fully meet the target of 'at least five a day', However, no guidelines are given as to how big or small a child's portion should be in comparison to the $80 \mathrm{~g}$ portion used in the adult recommendations. Due to the lack of specific recommendations it was decided that it would be more meaningful to look at children's intake in terms of eating frequencies rather than actual amounts to identify how many children were consuming fruit and vegetables five times per day. Very few children in this sample (20\%) were eating the recommended 5 portions of fruits and vegetables a day. In fact, almost $45 \%$ of the sample consumed fruit and vegetables on less than two occasions on the recording day and the main finding was that $80 \%$ of children were not meeting the target.

Table 4 Median daily intake of fruit according to awareness and preference scores

\begin{tabular}{ccccc}
\hline \multicolumn{5}{c}{ Fruit intake $(\mathrm{g})$} \\
\cline { 2 - 5 } & Median & $95 \% \mathrm{Cl}$ & IQR range & $P$-value \\
\hline Fruit awareness score & & & \\
1 & 0 & $0-284$ & $0-284$ & $<0.01$ \\
2 & 66 & $0-77$ & $0-129$ & \\
3 & 120 & $73-158$ & $71-224$ & \\
4 & 138 & $114-168$ & $71-221$ & \\
Fruit preference score & & & \\
0 & 0 & $0-205$ & $0-51$ & \\
1 & 118 & $73-250$ & $73-245$ & \\
2 & 117 & $71-150$ & $67-183$ & \\
3 & 72 & $62-114$ & $0-141$ & \\
4 & 151 & $133-195$ & $73-239$ & \\
\hline
\end{tabular}

$\mathrm{Cl}$ - confidence interval; IQR - interquartile range.
It is difficult to compare this finding with previous data as very little is published in this age group and data are presented in different ways. However one existing study, aiming to identify predictors of children's fruit and vegetable intakes, found that in a North London population of 564 children, aged 2-6 years, only 30\% ate fruit more than once a day and just $17 \%$ ate vegetables more than once per day ${ }^{20}$. No figures were given for the numbers of children actually achieving 5 portions a day but the figures must fall alarmingly short of the target.

In order to be able to compare data from the present study with data from the National Diet and Nutrition Survey (NDNS), consumption of fruit and vegetables needs to be presented in terms of grams of intake per day. The results show that in the current study median intakes of fruit and vegetables were $162 \mathrm{~g} \mathrm{day}^{-1}$. The majority of this was made up from the fruit intake in the diet, with

Table 5 Median daily intake of vegetables according to awareness and preference scores

\begin{tabular}{ccccc}
\hline \multicolumn{5}{c}{ Vegetable intake (g) } \\
\cline { 2 - 5 } & \multicolumn{5}{c}{ Median } & $95 \% \mathrm{Cl}$ & IQR & $P$-value \\
\hline \multicolumn{5}{c}{ Vegetable awareness score } \\
0 & 31 & $0-65$ & $0-74$ & 0.01 \\
1 & 28 & $24-31$ & $0-57$ & \\
2 & 32 & $28-58$ & $0-76$ & \\
3 & 65 & $29-99$ & $27-116$ & \\
Vegetable preference score & & \\
0 & 0 & $0-40$ & $0-52$ & \\
1 & 33 & $24-54$ & $0-59$ & \\
2 & 32 & $28-59$ & $0-79$ & \\
3 & 56 & $28-77$ & $0-88$ & \\
\hline
\end{tabular}

$\mathrm{Cl}$ - confidence interval; IQR - interquartile range. 
median intakes of vegetables averaging just $31 \mathrm{~g} \mathrm{day}^{-1}$ in this sample. The NDNS of children aged 1.5 to 4.5 years reported that children in their sample were consuming on average just $39 \mathrm{~g}$ of vegetables and $50 \mathrm{~g}$ of fruit daily ${ }^{21}$. A further study of 3-year-olds in South West England ( $n=863$ ) observed overall daily fruit and vegetable intakes of $124 \mathrm{~g}^{22}$. The average figures quoted in these former studies are based on mean values as opposed to medians, which are quoted in the present study. This does affect comparison of the data and mean estimates of fruit and vegetable intakes are likely to be higher than estimates based on median values due to the skewed nature of the data. The apparent higher intake, particularly of fruit, in the current study compared with other studies may be due to a number of, or a combination of, plausible explanations. For example, both the NDNS survey and the study in South West England both used food records/ diaries, completed by the main carer on behalf of the child, to assess intake of fruit and vegetables. Parental reports of young children's diets have been found to be accurate enough to be used for dietary surveillance ${ }^{23}$ although problems of underreporting, particularly when the children might be in childcare, are an obviously important issue. Conversely, although the CADET diaries were completed by the research team on behalf of the child, both nurseries and parents were aware of the subject of the 'Five for All' study and it is certainly possible that extra fruit and vegetables were incorporated into the children's diets on the data collection day. Previous research on lifestyle factors affecting fruit and vegetable consumption in adults found that belonging to a higher socio-economic group was a strong predictor of fruit and vegetable intake $^{24}$. However, this is unlikely to be an explanation for the high intakes experienced in the present study, as the study group was not from a particularly high socioeconomic area. Although the socio-economic status of individuals was not assessed directly, 25\% of households within the current study had no paid job and 30\% of households held no formal qualifications, indicating that the socio-economic status of these households would not be particularly high.

In adults it has been found that men tend to be the lowest consumers of fruit and vegetables ${ }^{25}$. A previous study of 2-6-year-olds found that boys ate vegetables less frequently than girls ${ }^{20}$. However, in the current study of 3- and 4-year-olds, no statistical differences were observed between the sexes. Age also had no observed effect on intake in this group of pre-school children. Statistically significant differences were observed in median fruit and vegetable intakes between children attending different nurseries and also between households with differing education levels. In the present study children coming from households with a higher education level (A-level or above) consumed significantly more fruit and vegetables than their peers from households with a lower education level $(P<0.01)$. This was also found to a lesser extent in the previous study of 2-6-year-olds, where parents with higher education level had children who ate more vegetables; but in that particular study the same effect was not observed for fruit intake ${ }^{20}$. The difference in average intakes between nurseries was staggering, with the lowest level at $90 \mathrm{~g} \mathrm{day}^{-1}$ and the highest at $270 \mathrm{~g} \mathrm{day}^{-1}(P<0.01)$. What is still unclear from these results is whether these differences are due to a lack of fruit and vegetables served in the pre-school setting or within the home. A recent study in Norfolk found that residential area deprivation predicted fruit and vegetable consumption independently of individual educational level and occupational social class ${ }^{26}$. It is possible that, in the present study, the nursery children attend is acting as a marker of residential area deprivation. If true, it is vital that the understanding of some of the community-level barriers to changing health behaviours is increased in order to attempt more effective interventions to reduce social inequalities in health.

The types of fruit and vegetables eaten by pre-school children is of interest as it is recommended that a variety of fruit and vegetables should be eaten in the daily diet to ensure a diversity of nutrient and phytochemical intakes ${ }^{8}$. Bananas and apples were by far the most popular fruits in the current sample, and peas and carrots were the most popular vegetables (excluding potatoes). Surprisingly, baked beans were eaten by only $10 \%$ of the sample on the recording day although previous studies found that of any vegetables baked beans were consumed in the greatest quantities and by up to $40 \%$ of the sample ${ }^{21}$. Although baked beans are included as a vegetable in the WHO recommendations, they can contain very high levels of sugar and salt and it is important that other types of vegetables are encouraged in this age group.

A previous study investigating the lifestyle factors affecting fruit and vegetable consumption in an adult sample found that those in the highest tertile of fruit and vegetable intakes consumed more varieties of fruit and vegetables than their peers in the lowest tertile of intake ${ }^{27}$. This suggests that it may be important to encourage new varieties of fruit and vegetables within the diet to be able to achieve recommended levels of intake. The present study backs this result up with the finding that as the children's awareness of different types of fruit and vegetables increased so did their median intakes $(P<0.01)$. The data presented here suggest that recognition, preference and intake of fruit and vegetables are closely connected. Fruits and vegetables that were recognised by more children were also liked by more children (e.g. 97\% of children recognised the apple and $92 \%$ reported liking the taste of apples). Conversely, fruits and vegetables that were recognised by the fewest children were also the least liked by children (e.g. only $21 \%$ of the children recognised the cauliflower and $28 \%$ reported liking the taste of cauliflower). These relationships, however, could lie in either direction and therefore 
causality cannot be assumed. A limitation of this part of the study was the range of fruit and vegetables used to assess recognition and preferences. The seven items were chosen because 'real' food items were used as opposed to food models, and these particular items were widely available and cheap to buy at each assessment period. Real food had to be used in the present study as one of the nurseries involved was a Montessori Nursery and the staff were not happy for models to be used. A greater variety of fruit and vegetables, incorporating those suitable for a multicultural sample, would be a more appropriate and cheaper alternative in future studies. In addition, it is difficult when working with children of this age to estimate how accurate their reporting of food preferences are, although the methodology was developed by a steering group that included both nursery teachers and classroom assistants. Taking these limitations into account, these data suggest that parents and caregivers need to ensure that children of pre-school age are exposed to a variety of fruit and vegetables in order to increase both awareness and liking, and in turn to increase consumption.

\section{Conclusion}

Fruit and vegetable intakes in this sample of pre-school children were far lower than the recommended levels of 5 portions a day. A greater diversity of intakes should be encouraged, and these data suggest that this may be attained by increasing children's awareness and liking by exposing them to a wider range of fruit and vegetables.

\section{Acknowledgements}

The 'Five for All' study was jointly funded by the Medical Research Council and the Big Lottery Fund. The 'Five for All' team would like to thank all participating nurseries including staff, parents and particularly the children for giving their valuable time and support to this project. No conflict of interest declared.

\section{References}

1 World Health Organization (WHO). Reducing Risks, Promoting Healthy Life. The World Health Report 2002. Geneva: WHO, 2002.

2 World Health Organization (WHO). Global Strategy on Diet, Physical Activity and Health. Geneva: WHO, 2004.

3 Block G, Patterson B, Subar A. Fruit, vegetables and cancer prevention: a review of the epidemiological evidence. Nutrition \& Cancer 1992; 18: 1-29.

4 Ness AR, Powles JW. Fruit and vegetables, and cardiovascular disease: a review. International Journal of Epidemiology 1997; 26: 1-13.

5 World Cancer Research Fund (WCRF)/American Institute for Cancer Research (AICR). Food, Nutrition and the Prevention of Cancer: A Global Perspective. Washington, DC: WCRF/AICR, 1997.

6 World Health Organization (WHO). Fruit and Vegetable
Promotion Initiative. Report of a WHO Fruit and Vegetable Initiative Expert Meeting, Geneva, Switzerland, 25-27 August 2003. Geneva: WHO, 2003.

7 World Health Organization (WHO). Diet, Nutrition and the Prevention of Chronic Diseases. WHO Technical Report Series No. 797. Geneva: WHO, 1990.

8 Committee on Medical Aspects of Food and Nutrition Policy. Nutritional Aspects of Cardiovascular Disease. Report on Health and Social Subjects No. 46. London: HMSO, 1994.

9 Committee on Medical Aspects of Food and Nutrition Policy. Nutritional Aspects of the Development of Cancer. Report on Health and Social Subjects No. 48. London: HMSO, 1998.

10 Cox DN, Anderson AS, Reynolds J, McKellar S, Mela DJ, Lean MEJ. Measuring fruit and vegetable intake: is five-a-day enough? European Journal of Clinical Nutrition 1997; 51: $177-80$.

11 Wang Y, Bentley ME, Zhai F, Popkin BM. Tracking of dietary intake patterns of Chinese from childhood to adolescence over a six-year follow-up period. Journal of Nutrition 2002; 132: $430-8$.

12 Bertheke Post G, de Vente W, Kemper HC, Twisk JW. Longitudinal trends in and tracking of energy and nutrient intake over 20 years in a Dutch cohort of men and women between 13 and 33 years of age: the Amsterdam growth and health longitudinal study. British Journal of Nutrition 2001; 85: $375-85$.

13 Resnicow K, Smith M, Baranowski T, Baranowski J, Vaughan R, Davis M. 2-year tracking of children's fruit and vegetable intake. Journal of the American Dietetic Association 1998; 98: $785-9$.

14 Robson PJ, Gallagher AM, Livingstone MB, Cran GW, Strain JJ, Savage JM, et al. Tracking of nutrient intakes in adolescence: the experiences of the Young Hearts Project, Northern Ireland. British Journal of Nutrition 2000; 84: $541-8$

15 Welten DC, Kemper HC, Post GB, Van Staveren WA, Twisk JW. Longitudinal development and tracking of calcium and dairy intake from teenager to adult. European Journal of Clinical Nutrition 1997; 51: 612-8.

16 Nicklas TA. Dietary studies of children: the Bogalusa Heart Study experience. Journal of the American Dietetic Association 1995; 95: 1127-33.

17 Forastiere F, Pistelli R, Sestini P, Fortes C, Renzoni E, Rusconi $\mathrm{F}$, et al. Consumption of fresh fruit rich in vitamin $\mathrm{C}$ and wheezing symptoms in children. SIDRIA Collaborative Group, Italy (Italian Studies on Respiratory Disorders in Children and the Environment). Thorax 2000; 55: 283-8.

18 Frear L, Greenwood DC, Cade JE. The development of a dietary assessment tool for school children aged 3 to 7 years. Proceedings of the Nutrition Society 2003; 62: 86A.

19 Gregory JR, Lowe S, Bates CJ, Prentice A, Jackson LV, Smithers G, et al. National Diet and Nutrition Survey: Young People aged 4 to 18 years. London: The Stationery Office, 2000.

20 Cooke LJ, Wardle J, Gibson EL, Sapochnik M, Sheiham A, Lawson M. Demographic, familial and trait predictors of fruit and vegetable consumption by pre-school children. Public Health Nutrition 2004; 7: 295-302.

21 Gregory JR, Collins DL, Davies PSW, Hughes JM, Clarke PC. National Diet and Nutrition Survey: Children aged 11/2 to 41/2 years. London: HMSO, 1995.

22 Emmett P, Rogers I, Symes C. Food and nutrient intakes of a population sample of 3 -year-old children in the South West of England in 1996. Public Health Nutrition 2002; 5 $55-64$.

23 Byers T, Trieber F, Gunter E, Coates R, Sowell A, Leonard S, et al. The accuracy of parental reports of their children's intake of fruits and vegetables: validation of a food 
frequency questionnaire with serum levels of carotenoids and vitamins C, A and E. Epidemiology 1993; 4: 350-5.

24 Pollard J, Greenwood D, Kirk S, Cade J. Lifestyle factors affecting fruit and vegetable consumption in the UK Women's Cohort Study. Appetite 2001; 37: 71-9.

25 Thompson RL, Margetts BM, Speller VM, McVey D. The health education authority's health and lifestyle survey 1993: who are the low fruit and vegetable consumers? Journal of Epidemiology and Community Health 1999; 53 : 294-9.
26 Shohaimi S, Welch A, Bingham S, Luben R, Day N, Wareham N, et al. Residential area deprivation predicts fruit and vegetable consumption independently of individual educational level and occupational social class: a cross sectional population study in the Norfolk cohort of the European Prospective Investigation into Cancer (EPIC-Norfolk). Journal of Epidemiology and Community Health 2004; 58: 686-91.

27 Pollard J, Greenwood D, Cade J. Lifestyle factors affecting fruit and vegetable consumption in the UK Women's Cohort Study. Appetite 2001; 37: 71-9. 